\title{
Structure and long-term change in the zonal asymmetry in Antarctic total ozone during spring
}

\author{
A. V. Grytsai ${ }^{1}$, O. M. Evtushevsky ${ }^{1}$, O. V. Agapitov $^{1}$, A. R. Klekociuk ${ }^{2}$, and G. P. Milinevsky ${ }^{1}$ \\ ${ }^{1}$ National Taras Shevchenko University of Kyiv, Kyiv, Ukraine \\ ${ }^{2}$ Australian Government Antarctic Division, Kingston, Australia
}

Received: 13 October 2006 - Revised: 10 January 2007 - Accepted: 15 January 2007 - Published: 8 March 2007

\begin{abstract}
The quasi-stationary asymmetry of total ozone over Antarctica during spring is studied by TOMS data during the period 1979-2005. Statistics on the amplitude and longitudinal position of zonal anomalies are obtained from the distribution of total ozone along seven individual latitudes at 5-degree intervals between $50^{\circ} \mathrm{S}$ and $80^{\circ} \mathrm{S}$. As shown by the September-November means, the mid-latitude collar of ozone-rich stratospheric air has a sub-Antarctic maximum with a mean location in the quadrant $90^{\circ} \mathrm{E}-180^{\circ} \mathrm{E}$ and a total ozone level of about $380 \mathrm{DU}$ between $50^{\circ} \mathrm{S}$ and $60^{\circ} \mathrm{S}$. The steady displacement and elongation of the ozone hole under the influence of planetary waves causes a zonal anomaly of low ozone in the sector $0^{\circ}-60^{\circ} \mathrm{W}$ with total ozone levels of about $200 \mathrm{DU}$ between $70^{\circ} \mathrm{S}$ and $80^{\circ} \mathrm{S}$. Climatologically, the highest amplitude of the zonal anomaly is $57.2 \pm 13.5 \mathrm{DU}$ (relative asymmetry of $32 \%$ between high and low ozone levels) at $65^{\circ} \mathrm{S}$ latitude.
\end{abstract}

A significant eastward shift of approximately $45^{\circ}$ in longitude is observed in the total ozone minimum over the Weddell Sea - South Atlantic sector during 1979-2005, whereas the zonal maximum is relatively stable in location. Also apparent is a long-term shift in tropopause temperature distribution in the region.

The geographical distribution of the zonal extremes in total ozone for the seven latitudes shows that (i) the extremes exhibit sensitivity to the shape of the Antarctic continent, (ii) the stationarity of the extremes increases poleward above the edge of continent and (iii) the positions of the extremes at the higher latitudes tend to follow the meridionally oriented elements of orography. It is suggested that the radiative influence of Antarctica contributes to the formation of this pattern. Anomalies in the horizontal structure of the tropopause, which appear related to orography, support this view.

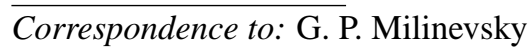

(gmilin@univ.kiev.ua)
Mechanisms involved in the formation and decadal change in the total ozone asymmetry, as well as possible influences of the asymmetry on the stratospheric thermal regimes and regional UV irradiance redistribution are discussed.

Keywords. Atmospheric composition and structure (Pressure, density, and temperature) - Meteorology and atmospheric dynamics (Middle atmosphere dynamics; Waves and tides)

\section{Introduction}

Quasi-stationary structures in the spatial distribution of the total ozone column (TOC) are a characteristic property of the global ozone field. Zonal asymmetry is an important feature of these structures. Similar to other atmospheric variables (e.g. pressure, temperature and geopotential height), the deviation of TOC from the zonal mean is a measure of zonal asymmetry. In the Southern Hemisphere, the quasistationary wave of zonal wave number 1 is the dominant feature of the total ozone field (Wirth, 1993). Here, zonal asymmetry is represented by one region of low ozone and another region of high ozone, and these regions are characteristically located in approximately opposing longitudinal sectors.

There are two main consequences of the zonal asymmetry in TOC. One of these is the existence of a longitudinal dependence of the ozone trend (Niu et al., 1992; Hood and Zaff, 1995; Peters and Entzian, 1999; Efstathiou et al., 2003). The second consequence is the appearance of large regional anomalies in total ozone. These are observed when the asymmetry is caused by the displacement of the stratospheric polar vortex from its symmetric position relative to the pole due to planetary wave activity (James et al., 2000; Calisesi et al., 2001). Such events are often combined with tropospheric cyclones and anticyclones that strengthen the TOC anomalies (Engelen, 1996; Vigliarolo et al., 2005).

Published by Copernicus GmbH on behalf of the European Geosciences Union. 
In the Arctic region, regional anomalies of low ozone are often observed over Europe in winter due to displacement of the stratospheric polar vortex. These can exceed -60 Dobson Units (DU) and reach latitudes of $60^{\circ} \mathrm{N}$ (James et al., 2000) and even as far equatorward as $47^{\circ} \mathrm{N}$ (Calisesi et al., 2001). In the Antarctic region, where the ozone hole exists during the austral spring, displacement of the vortex causes low-ozone events equatorward as far as $55^{\circ} \mathrm{S}$ (Vigliarolo et al., 2005) or $50^{\circ} \mathrm{S}$ (Perez et al., 2000). This can potentially increase the level of harmful UV radiation over the populated southern edge of South America (Bernhard et al., 2000; Zaller et al., 2002).

Previously, Grytsai et al. (2005) showed that the zonal maximum and minimum in total ozone measured at $65^{\circ} \mathrm{S}$ by the Total Ozone Mapping Spectrometer (TOMS) exhibit different long-term behaviour. The maximum was stable during 1979-2003 with a mean longitude of $152^{\circ} \mathrm{E}$, whereas the minimum drifted eastward within the longitudinal sector $60^{\circ} \mathrm{W}-0^{\circ} \mathrm{E}$ with a mean rate of $23.6 \pm 7.2^{\circ}$ per decade.

In order to examine the existence of similar behaviour at other southern latitudes, we have extended the analysis of Grytsai et al. (2005) to latitudes of $50^{\circ} \mathrm{S}-80^{\circ} \mathrm{S}$. The remainder of this paper is organised as follows. The data and analysis method are briefly described in Sect. 2. In Sect. 3, the structure of the springtime total ozone field in the Antarctic and sub-Antarctic regions is described using TOMS data. The existence of two asymmetric anomalies in the ozone field is highlighted. The degree of the total ozone zonal asymmetry, its spatial structure and long-term behaviour are statistically described in Sect. 4. The results are discussed in Sect. 5 and conclusions are given in Sect. 6.

\section{Data and analysis method}

TOMS Version 8 total ozone data (http://toms.gsfc.nasa.gov/ ftpdata.html) were used for the analysis presented here. Data were obtained for the austral springs (September-November) of 1979-2005, except for 1993-1995, due to the absence of Version 8 data. Thus, statistics for 24 springs over a 27-year period are presented. As in Grytsai et al. (2005), daily longitudinal distributions of total ozone at individual latitudes were analyzed to obtain 3-month (September-November) means.

We focus on these months, as this is generally when both the chemical and dynamical contributions to the zonal asymmetry act, and transport processes associated with the breakdown of the polar vortex are less important. The vortex generally begins to break down in November, resulting in mixing of polar and lower latitude air. The final dissipation of the vortex exhibits interannual variability, and since the early 1990s has shown a trend of occurring later in the year and extending into early December (Waugh and Randel, 1999; WMO, 2003). On average, the ending date of our seasonal interval is close to the end of vortex season, and we expect that the influence of post-vortex conditions on our analysis to be minimal.

The TOMS data are presented as 1-degree averages in bins centered from $89.5^{\circ} \mathrm{S}$ to $89.5^{\circ} \mathrm{N}$. This work considers seven 1-degree latitude bands at 5-degree intervals between $50.5^{\circ} \mathrm{S}$ and $80.5^{\circ} \mathrm{S}$. In the text we indicate integer values for these latitude bands, for example, $50^{\circ} \mathrm{S}$ for $50.5^{\circ} \mathrm{S}$, and use the term "latitude" instead of "latitude bands" for simplicity. The latitude range $50^{\circ} \mathrm{S}-80^{\circ} \mathrm{S}$ was selected to cover the edge region of ozone hole, where wave disturbances are strongly pronounced. Note that the spring TOMS data for $80^{\circ} \mathrm{S}$ are only annually available after 14 September and so our 3month statistics for this latitude covers 78 days, or $86 \%$ of the total spring days. The effect of this on the averaging is not likely to be important.

A few parameters are introduced to statistically describe the TOC asymmetry using the 3-month mean distribution along individual latitudes. The extreme level of total ozone at the quasi-stationary zonal wave ridge and trough are denoted as $\mathrm{TOC}_{\max }$ and $\mathrm{TOC}_{\min }$, respectively. Two quantities are used to characterize the degree of zonal asymmetry: (i) the amplitude of the zonal wave $A_{z w}$, calculated as the halfdifference of $\mathrm{TOC}_{\max }$ and $\mathrm{TOC}_{\min }$, namely $A_{z w}=\left(\mathrm{TOC}_{\max }-\right.$ $\left.\mathrm{TOC}_{\min }\right) / 2$, and (ii) the relative asymmetry $A_{\text {rel }}=\left(\mathrm{TOC}_{\max }-\right.$ $\left.\mathrm{TOC}_{\min }\right) \times 100 / \mathrm{TOC}_{\max }$, as a percentage difference between the total ozone levels at the wave extremes.

Note that a predominance of the zonal wave 1 results in a rather wide longitudinal extension of the zonal maximum and minimum. Consideration of the individual latitudes simplifies the problem of determining the position of the wave ridge and trough, as two points can present the zonal extremes at given latitude. Such an approach allows quantitative estimation of variations in the extreme positions, in spite of the zonally smooth shape of the 3-month mean distributions of total ozone.

The statistics of the TOC asymmetry were compared with distributions of the tropopause pressure and geopotential height at several pressure levels, using NCEP-NCAR reanalysis data (http://www.cdc.noaa.gov).

\section{The two ozone anomalies of the Antarctic region}

Figure 1 shows the zonal asymmetry in total ozone during the Antarctic spring. As an example, the October-mean fields have been created using TOMS data for latitudes $45^{\circ} \mathrm{S}-$ $90^{\circ} \mathrm{S}$. Selected years of the 1979-2005 period are shown. It can be seen that two anomalies of opposite sign exist in the distribution of total ozone. Each of these contributes to the zonal asymmetry in this region.

The first feature of the asymmetry is a band of ozone-rich air at mid- and sub-polar latitudes. As shown in Fig. 1, its longitudinal extent reaches or exceeds $180^{\circ}$ and it is located predominantly around East Antarctica. Maximum TOC levels of more than $400 \mathrm{DU}$ (red in Fig. 1) are common in this 


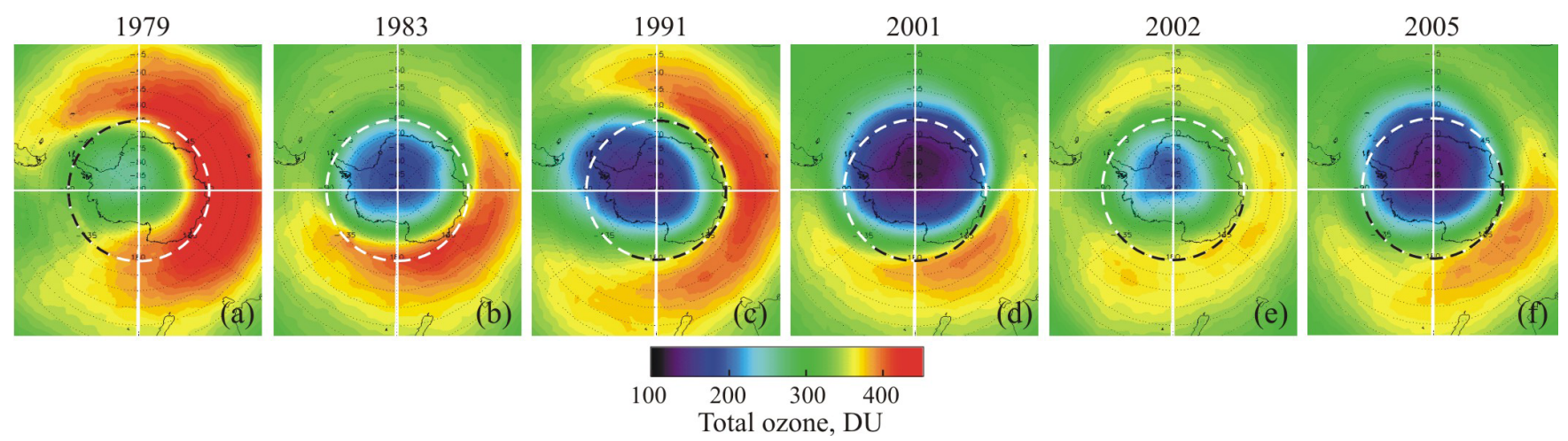

Fig. 1. October mean fields of total ozone over the southern latitudes $45^{\circ} \mathrm{S}-90^{\circ} \mathrm{S}$ obtained from TOMS data. The dashed circle marks latitude $65^{\circ} \mathrm{S}$.

region during October. The characteristic "collar" region of high ozone surrounding the ozone-poor Antarctic polar vortex results from poleward transport associated with the descending branch of the Brewer-Dobson cell that is dynamically blocked by the polar vortex (Holton et al., 1995).

In the meridional direction, this asymmetrical pattern has an ozone maximum at latitudes $50^{\circ} \mathrm{S}-60^{\circ} \mathrm{S}$ and an equatorward boundary at $\sim 40^{\circ} \mathrm{S}$. A similar description of the "ozone collar" as a latitude band, centred at about $55^{\circ} \mathrm{S}$, with a large ozone mixing ratio is given by Mariotti et al. (2000). Sometimes the ozone-rich air can reach the edge of the Antarctic continent (i.e. latitudes of about $70^{\circ} \mathrm{S}-75^{\circ} \mathrm{S}$ ), as in October 1979 and 1983 (Figs. 1a and b, respectively). The zonal asymmetry has a peak-to-peak amplitude difference of more than $100 \mathrm{DU}$. This is in comparison with the monthly mean level of $\sim 300 \mathrm{DU}$ in the TOC background field (green in Fig. 1). As can be seen in Fig. 1a, the asymmetry was present in the pre-ozone-hole years, as well (Fig. 1a).

The second feature of the asymmetry is the ozone hole, which is usually displaced relative to the pole by the influence of stationary planetary wave number 1 on the polar vortex (Waugh and Randel, 1999). The ozone hole contains low ozone air, and the TOC level of $220 \mathrm{DU}$ is often used to define the boundary and area of the hole (WMO, 2003).

In the years of large ozone holes, the off-pole position and elongation of the hole favour the equatorward penetration of low ozone air to latitudes of $55^{\circ} \mathrm{S}-60^{\circ} \mathrm{S}$. As seen in Figs. 1c, d and f, this was the case in October 1991, 2001 and 2005, respectively. The situation in October 1991 (Fig. 1c) was notable in causing average TOC levels of about 220$250 \mathrm{DU}$ adjoining the ozone hole edge to be experienced by populated areas of southern South America. Figure 1 shows that the displacement of the ozone hole typically occurs towards the longitude quadrant of $90^{\circ} \mathrm{W}-0^{\circ} \mathrm{E}$. This feature of the asymmetry can have a peak-to-peak amplitude of greater than $100 \mathrm{DU}$. The combined effects of the two anomalies can produce a total asymmetry between $200 \mathrm{DU}$ and $400 \mathrm{DU}$, that corresponds to relative asymmetry $A_{\text {rel }} \sim 50 \%$.
As mentioned above, the high levels of stratospheric ozone around Antarctica are dynamically accumulated outside the polar vortex because the vortex effectively prevents mixing of mid-latitude and polar air. The low ozone levels inside the ozone hole arise due to the chemical processes which result in the enhanced destruction of polar ozone when the Sun returns in spring. Therefore, the first and second features of the TOC asymmetry have dynamical and chemical origins, respectively. Although the ozone hole can move off the pole and elongate under the influence of planetary waves, these sources of zonal asymmetry are chemical in origin. We use the terms "dynamical maximum" and "chemical minimum" to emphasize the basic process providing enhanced ozone accumulation and losses, respectively. Our visual review of TOMS monthly mean total ozone fields over July-December of 1979-2005 suggests that the sub-polar ozone maximum and ozone hole typically have a similar seasonal change with both having maximum intensity in September-October.

\section{Zonal asymmetry statistics for 1979-2005}

\subsection{Zonal wave amplitude}

Figure 2 shows the individual September-November TOC means for the seven latitudes and 24 years considered. The individual panels reveal that the mean ozone distribution has a wave-like zonal behaviour, which exhibits interannual and spatial variability characteristics.

It can be seen that the lowest zonal asymmetry and variability of the zonal wave is observed at $50^{\circ} \mathrm{S}$. The highest wave amplitude appears at $60^{\circ} \mathrm{S}-70^{\circ} \mathrm{S}$, near the edge of the ozone hole. The general trend in long-term polar ozone loss is also apparent in Fig. 2. For example, at $80^{\circ} \mathrm{S}$ the average TOC level decreased from $\sim 300 \mathrm{DU}$ to $\sim 150 \mathrm{DU}$ during the interval 1979-2005.

Table 1 presents the September-November characteristics of the quasi-stationary wave in total ozone averaged over the 24 springs. The decadal trend from a linear fit to the 


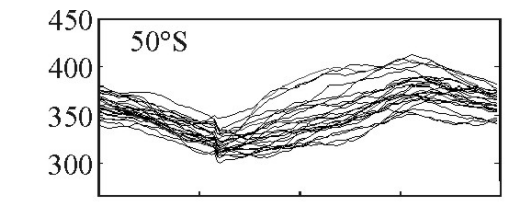

(a)
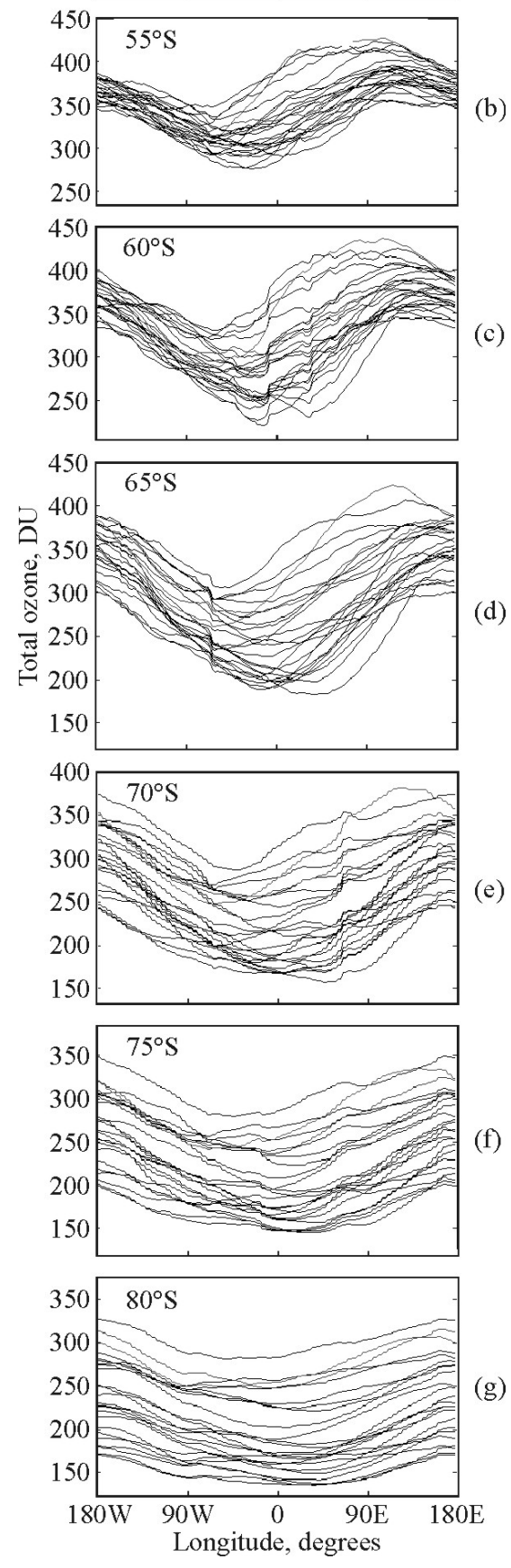

Fig. 2. Interannual variations of the mean spring distribution of the TOMS total ozone at the 7 latitudes between $50^{\circ} \mathrm{S}$ and $80^{\circ} \mathrm{S}$.

data and its standard deviation are given for the zonal maximum $\mathrm{TOC}_{\max }$ and minimum $\mathrm{TOC}_{\min }$ and zonal wave amplitude $A_{z w}$. The latitudinal distribution of the mean values


(b)

Fig. 3. (a) Mean total ozone at the zonal wave extremes and (b) mean amplitude of zonal wave in total ozone at the seven latitudes with 5-degree step between $50^{\circ} \mathrm{S}$ and $80^{\circ} \mathrm{S}$ over the 24 springs of 1979-2005.

of $\mathrm{TOC}_{\max }$ and $\mathrm{TOC}_{\min }$ is shown in Fig. 3a. In the region of the zonal maximum, at the sub-polar latitudes of $50^{\circ} \mathrm{S}-$ $60^{\circ} \mathrm{S}$, an approximately constant TOC level of about $380 \mathrm{DU}$ is observed (see also $\mathrm{TOC}_{\max }$ in Table 1). In the region of the zonal minimum, at the polar latitudes of $70^{\circ} \mathrm{S}-80^{\circ} \mathrm{S}$, the total ozone has a mean level of about $200 \mathrm{DU}\left(\mathrm{TOC}_{\min }\right.$ in Table 1).

The largest trends in $\mathrm{TOC}_{\min }$ of between $-30 \mathrm{DU} / \mathrm{dec}$ ade and $-38 \mathrm{DU} /$ decade are observed within the latitude zone $60^{\circ} \mathrm{S}-80^{\circ} \mathrm{S}$ (Table 1). Niu et al. (1992) obtained a maximum value for the spring trend during 1978-1990 of $-23 \% /$ decade at $65^{\circ} \mathrm{S}$. Our values over $1979-2005$ correspond to $-10 \% /$ decade to $-13 \% /$ decade or about a factor of two less than Niu et al. (1992). This difference could be caused by the fact that since approximately 1997 ozone losses have leveled off in this region (Yang et al., 2005). Slowing of the downward trend during the most recent decade results in lower trend values during 1979-2005 relative to $1978-1990$.

The vertical distance between the two curves in Fig. 3a indicates that the asymmetry degree varies with latitude. The largest difference (i.e. the highest amplitude of the zonal 
Table 1. September-November mean characteristics of the quasi-stationary TOC distribution at seven latitudes from $50^{\circ} \mathrm{S}$ to $80^{\circ} \mathrm{S}$ averaged over 1979-2005.

\begin{tabular}{lcccccc}
\hline Lat., ${ }^{\circ} \mathrm{S}$ & $\mathrm{TOC}_{\max }, \mathrm{DU}$ & $\mathrm{TOC}_{\min }, \mathrm{DU}$ & $A_{z w}, \mathrm{DU}$ & $\begin{array}{c}\mathrm{TOC}_{\max } \text { trend, } \\
\text { DU/decade }\end{array}$ & $\begin{array}{c}\mathrm{TOC}_{\min } \text { trend, } \\
\text { DU/decade }\end{array}$ & $\begin{array}{c}A_{z w} \text { trend, } \\
\text { DU/decade }\end{array}$ \\
\hline 50 & $378.3 \pm 15.9$ & $322.3 \pm 10.5$ & $28.0 \pm 6.6$ & $-8.4 \pm 3.6$ & $-8.5 \pm 2.0$ & $0.0 \pm 1.7$ \\
55 & $386.5 \pm 19.4$ & $310.3 \pm 17.9$ & $38.1 \pm 9.1$ & $-12.0 \pm 4.2$ & $-17.4 \pm 2.6$ & $2.7 \pm 2.2$ \\
60 & $381.2 \pm 23.4$ & $279.8 \pm 29.9$ & $50.7 \pm 12.0$ & $-15.1 \pm 5.0$ & $-29.9 \pm 4.1$ & $7.4 \pm 2.6$ \\
65 & $354.0 \pm 30.9$ & $239.5 \pm 39.1$ & $57.2 \pm 13.5$ & $-19.2 \pm 6.7$ & $-37.8 \pm 5.8$ & $9.3 \pm 2.8$ \\
70 & $307.1 \pm 39.7$ & $213.8 \pm 39.7$ & $46.6 \pm 11.8$ & $-25.1 \pm 8.5$ & $-35.9 \pm 6.5$ & $5.4 \pm 2.8$ \\
75 & $266.8 \pm 43.2$ & $196.7 \pm 41.1$ & $35.1 \pm 10.0$ & $-28.6 \pm 9.1$ & $-35.4 \pm 7.2$ & $3.4 \pm 2.4$ \\
80 & $239.4 \pm 46.8$ & $190.7 \pm 43.8$ & $24.4 \pm 7.9$ & $-29.5 \pm 10.1$ & $-34.3 \pm 8.4$ & $2.4 \pm 1.9$ \\
\hline
\end{tabular}

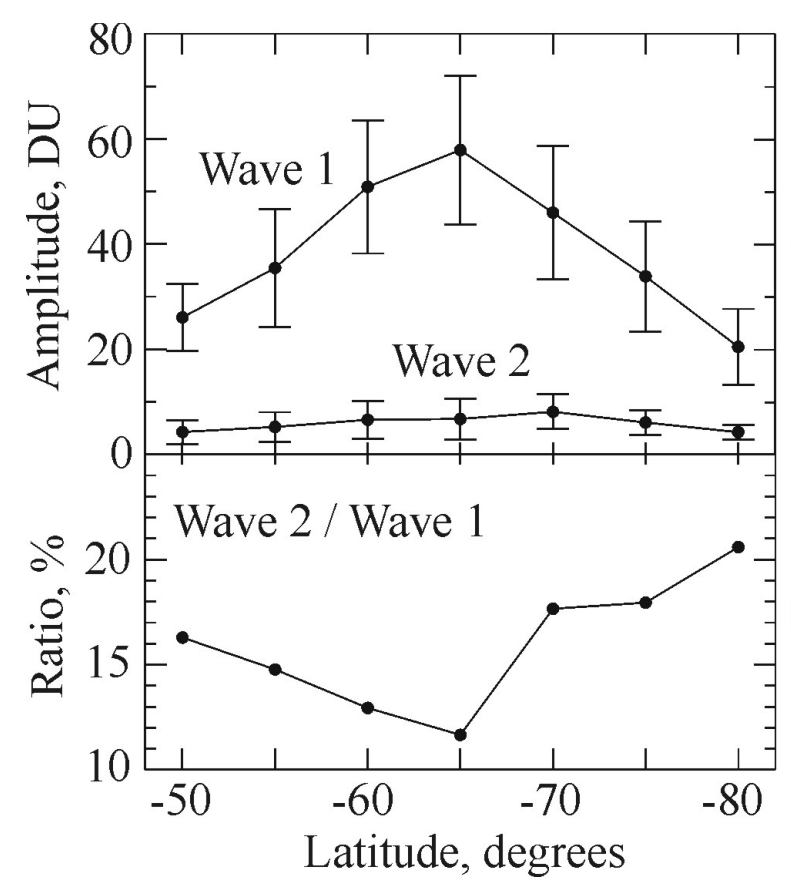

Fig. 4. As in Fig. 3, but for (a) the amplitudes of zonal wave 1 and 2 and (b) the amplitude ratio between wave 2 and wave 1 . The wave amplitudes were obtained using Fourier decomposition.

wave) is observed at latitude $65^{\circ} \mathrm{S}$ (Fig. 3b). At this latitude, the wave amplitude is $A_{z w}=57.2 \pm 13.5 \mathrm{DU}$ (Table 1) and the relative asymmetry is $A_{\text {rel }}=32 \%$. The zonal wave amplitude is approximately half the peak value at latitudes of $50^{\circ} \mathrm{S}$ and $80^{\circ} \mathrm{S}$.

Figure 4 illustrates the relationship between the characteristics of zonal wave numbers 1 and 2 obtained from Fourier decomposition. Stationary wave 1 provides the main contribution to the zonal asymmetry in TOC. The wave 2 amplitude varies between 4 and $8 \mathrm{DU}$, while the amplitude ratio between wave 2 and wave 1 varies between $12 \%$ and $21 \%$, reaching a minimum value at $65^{\circ} \mathrm{S}$ (Fig. 4b). The peak of the wave 2 amplitude distribution $\left(70^{\circ} \mathrm{S}\right)$ occurs approximately $5^{\circ}$ poleward of that for wave $1\left(65^{\circ} \mathrm{S}\right)$. This results in the in-


Fig. 5. Variation (circles) and trend (lines) of longitudinal positions of the zonal wave (a) ridge and (b) trough for the springs of 19792005 at the seven latitudes between $50^{\circ} \mathrm{S}$ and $80^{\circ} \mathrm{S}$. Colours are labelled on the right side of plot (b).

crease of the wave 2 to wave 1 ratio at the polar latitudes of $70^{\circ} \mathrm{S}-80^{\circ} \mathrm{S}$, which is apparent in Fig. $4 \mathrm{~b}$.

The mean characteristics of the TOC zonal asymmetry discussed above describe the steady climatological features of the total ozone distribution in the Antarctic spring over 19792005. We now turn our attention to the temporal behaviour of the wave characteristics. 


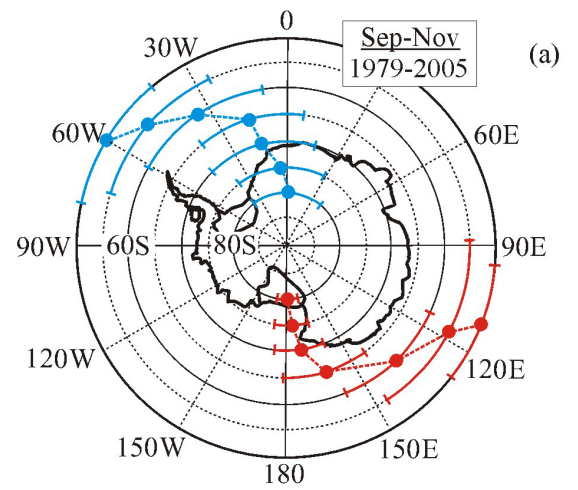

(a)

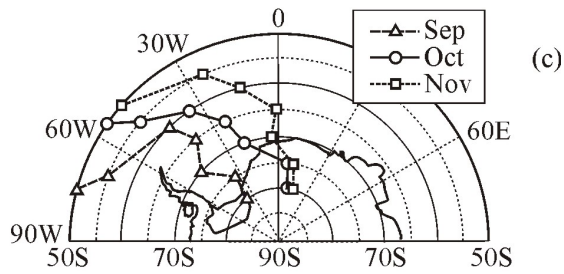

(c)


Fig. 6. (a) The 1979-2005 mean longitudinal position of the zonal wave extremes with the standard deviation bars; (b) initial (1979, closed circles) and final (2005, open circles) extreme positions obtained from the linear fits shown in Fig. 5; (c) monthly mean positions of zonal minimum for September (triangles), October (circles) and November (squares) and (d, e) eastward shift of zonal minimum during 1979-2005 in October and November, respectively, estimated by linear fit.

\subsection{Position of zonal wave extremes}

Figure 5 shows interannual variations and trends for the mean longitude of the spring zonal wave extremes at the seven latitudes. Table 2 gives estimates of the mean longitudinal positions of the extremes and their trends from a least-squares linear fit.

The trends presented by Grytsai et al. (2005) are confirmed by the results for the latitude $65^{\circ} \mathrm{S}$, and are similar to those at the other latitudes. The wave ridge is longitudinally stable, except at $60^{\circ} \mathrm{S}$, where a trend of $7.9 \pm 5.0^{\circ} \mathrm{E} /$ decade (significant at the $1 \sigma$ level) exists (see column "TOC $\mathrm{T}_{\max }$ shift" in Table 2). The wave trough exhibits an eastward shift for all seven latitudes, which is significant at the $2 \sigma$ level (see standard deviation in the column "TOC ${ }_{\min }$ shift" in Table 2).

A more general view of the results of Fig. 5 and Table 2 is presented in Fig. 6. The latitude-longitude distribution of the TOC zonal extremes averaged over the 24 springs is shown in Fig. 6a. The range in the standard deviation at each of the seven latitudes is marked.

On average, the ozone minimum is located in the longitude range $60^{\circ} \mathrm{W}-0^{\circ} \mathrm{E}$, although the longitudinal deviations widen this sector to about $80^{\circ} \mathrm{W}-30^{\circ} \mathrm{E}$ (at the $1 \sigma$ level). The ozone maximum occupies the quadrant $90^{\circ} \mathrm{E}-180^{\circ} \mathrm{E}$. A general decrease in the deviations toward the pole is clearly seen, especially in the positions of zonal maxima. Additionally, the mean positions of the maxima at latitudes of $65^{\circ} \mathrm{S}-80^{\circ} \mathrm{S}$ are concentrated within the narrow sector $162^{\circ} \mathrm{E}-180^{\circ} \mathrm{E}$ (see also Table 2).

The long-term tendencies are displayed in Fig. $6 \mathrm{~b}$ by initial (1979, closed circles) and final (2005, open circles) positions of extremes estimated by a linear fit of their interannual variations (Fig. 5b). The eastward shift of the zonal minimum at each of the latitudes and the stability of the zonal maximum, except for latitudes $50^{\circ} \mathrm{S}-60^{\circ} \mathrm{S}$, are seen. The average shift distance of the $\mathrm{TOC}_{\min }$ positions at the seven latitudes in Fig. $6 \mathrm{~b}$ is $45^{\circ}$, which, based on a Monte-Carlo

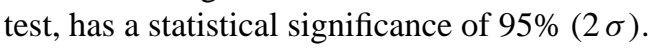

As shown by Niu et al. (1992), the area of peak ozone decline shifted eastward from September to November during 1978-1990. At latitude $65^{\circ} \mathrm{S}$, the large negative trends appeared from $180^{\circ} \mathrm{W}$ to $120^{\circ} \mathrm{W}$ in September, from $100^{\circ} \mathrm{W}$ to $0^{\circ} \mathrm{E}$ in October and from $20^{\circ} \mathrm{W}$ to $40^{\circ} \mathrm{E}$ in November (Fig. 2b in Niu et al., 1992). Niu et al. (1992) found that on average, the eastward shift over the period 1978-1990 was $100^{\circ}$ in September to October and $60^{\circ}$ in October to November.

In the ozone field, as shown in Fig. 6c, the month-to-month shift of the TOC $_{\min }$ positions over 1979-2005 is much less, 
Table 2. Mean spring longitudes of the zonal wave maximum and minimum $\left(\mathrm{TOC}_{\max }\right.$ and $\mathrm{TOC}_{\min }$, respectively) and their decadal changes in the period 1979-2005. One standard deviation is given.

\begin{tabular}{ccccc}
\hline $\begin{array}{c}\text { Lat., } \\
{ }^{\circ} \mathrm{S}\end{array}$ & $\begin{array}{c}\mathrm{TOC}_{\max } \\
\text { longitude, }{ }^{\circ} \mathrm{E}\end{array}$ & $\begin{array}{c}\mathrm{TOC}_{\min } \\
\text { longitude, }{ }^{\circ} \mathrm{E}\end{array}$ & $\begin{array}{c}\mathrm{TOC}_{\max } \text { shift, } \\
{ }^{\circ} \text { E/decade }\end{array}$ & $\begin{array}{c}\mathrm{TOC}_{\min } \text { shift, } \\
{ }^{\circ} \text { E/decade }\end{array}$ \\
\hline 50 & $112.1 \pm 16.1$ & $-60.2 \pm 19.1$ & $2.9 \pm 4.0$ & $9.5 \pm 4.4$ \\
55 & $117.7 \pm 29.1$ & $-49.0 \pm 23.8$ & $5.6 \pm 7.3$ & $14.8 \pm 5.1$ \\
60 & $136.7 \pm 20.9$ & $-34.8 \pm 26.4$ & $7.9 \pm 5.0$ & $17.5 \pm 5.6$ \\
65 & $161.9 \pm 18.7$ & $-17.6 \pm 24.6$ & $3.6 \pm 4.7$ & $16.4 \pm 5.2$ \\
70 & $171.3 \pm 13.5$ & $-15.2 \pm 31.4$ & $-0.8 \pm 3.4$ & $18.9 \pm 6.9$ \\
75 & $176.3 \pm 11.9$ & $-5.4 \pm 33.8$ & $-0.8 \pm 3.0$ & $21.2 \pm 7.3$ \\
80 & $179.6 \pm 11.3$ & $0.8 \pm 39.8$ & $1.8 \pm 2.8$ & $23.5 \pm 8.8$ \\
\hline
\end{tabular}

and at $65^{\circ} \mathrm{S}$ equals about $15^{\circ}$ and $25^{\circ}$, respectively. The successive shift in October and November between latitudes $50^{\circ} \mathrm{S}$ and $70^{\circ} \mathrm{S}$ is on average $20^{\circ}$. Generally, the location of the lowest total ozone area in Antarctica means the highest ozone losses and, hence, the highest negative trends. The average location of the extreme downward trend in Niu et al. (1992) is about $70^{\circ} \mathrm{W}$ and the $\mathrm{TOC}_{\min }$ position in Fig. 6c is on average at $30^{\circ} \mathrm{W}$. As for the trend values (see Sect. 4.1 above), this difference, as well as the difference in shift distance, can be attributed to the different length of the data time series. During 1980s, ozone losses had a higher rate than during the last decade and, possibly, similar behaviour could be peculiar to the month-to-month zonal shift.

An indication of the origin of the September to November eastward shift is revealed from the analysis of the monthly decadal shift. As in Fig. $6 \mathrm{~b}$ for spring on the whole, the longterm changes were estimated from a linear fit for each spring month. In September any significant longitudinal shift during 1979-2005 is not observed. The average distribution of the $\mathrm{TOC}_{\text {min }}$ positions for this month is presented by triangles in Fig. 6c. In October and November the average eastward shift is $45^{\circ}$ and $70^{\circ}$, respectively (Figs. $6 \mathrm{~d}$, e).

Note that the relative stability of the initial $\mathrm{TOC}_{\min }$ distribution in October and November (Figs. 6d, e) coincides with the average distribution for September (Fig. 6c). As a result, a successive increase in the decadal shift distance from September to November gives the effect of an eastward shift in the monthly mean positions (Fig. 6c).

A similar cause possibly underlies the longitudinal shift of the large negative trends during the spring months in Niu et al. (1992). Based on our results, it is concluded that the changes in October and November are only responsible for the decadal eastward shift of the $\mathrm{TOC}_{\min }$ positions in Fig. $6 \mathrm{~b}$, because September does not contribute to this tendency.

Note further that the configuration of the extremes in Fig. 6 also gives an indication of an orographic influence. Initial positions of the zonal minimum (for 1979 in Figs. 6b, d, e) and the mean positions of the wave maximum (Fig. 6a) seem to outline the boundary of the Antarctic continent. This unexpected result was first reported by Grytsai et al. (2007). The initial positions of the wave minima are oriented along the Antarctic Peninsula, close to the west coastline of the Weddell Sea at $\sim 60^{\circ} \mathrm{W}, 65^{\circ} \mathrm{S}-75^{\circ} \mathrm{S}$ and deviate toward South America at the lower latitudes. The positions of the wave maxima resemble the contours of Victoria Land and Wilkes Land and approach close to the coastline of the Ross Sea at $\sim 180^{\circ} \mathrm{E}, 70^{\circ} \mathrm{S}-80^{\circ} \mathrm{S}$. The wave extremes appear to follow the meridionally oriented elements of the continent boundary and deviate counterclockwise at the lower latitudes.

The long-term eastward shift of the zonal minimum alters the location and configuration of the extremes in this region. However, the meridional component in the final positions of the minima at the high latitudes (open circles in Figs. 6b, d, e) should be noted.

The monthly mean ozone fields of Fig. 1 do not show obvious indications of such a pattern. We have examined the average ozone distribution over the Antarctic region using a contour representation to simplify a comparison of the shape of the TOC at discrete levels with the coastline. The contours of the total ozone and its zonal deviation are shown in Figs. 7a and $b$, respectively. They are obtained by averaging over the 24 springs. The area of the low ozone is displaced relative to the pole approximately along the Greenwich meridian by about $10^{\circ}$. This effect can be attributed to the influence of stationary planetary wave 1 on the polar vortex. Note that the continental boundary of Antarctica also takes an asymmetric position relative to the pole, being displaced toward the Eastern Hemisphere.

Secondly, in Fig. 7a, the shape of the TOC contours over Antarctica appears similar to the shape of the continental boundary in the sector $0^{\circ}-300^{\circ} \mathrm{E}$. The ozone contours over the Antarctic plateau deviate in a manner similar to the coastline at longitudes of the Ross Sea $\left(\sim 180^{\circ} \mathrm{E}\right)$ and the Amery Ice Shelf $\left(\sim 70^{\circ} \mathrm{E}\right)$, which are shown by arrows in Fig. 7a. In the sector of the Antarctic Peninsula and Weddell Sea $\left(0^{\circ}-\right.$ $60^{\circ} \mathrm{W}$ ) the effect of orography is not clearly visible and a possible cause of this is discussed below in Sect. 5.2.

Contours of the zonal extremes in Fig. $7 b$ are also deformed to a greater or lesser extent over the edge of Antarctica. Small-scale deviations in their shape are seen over 

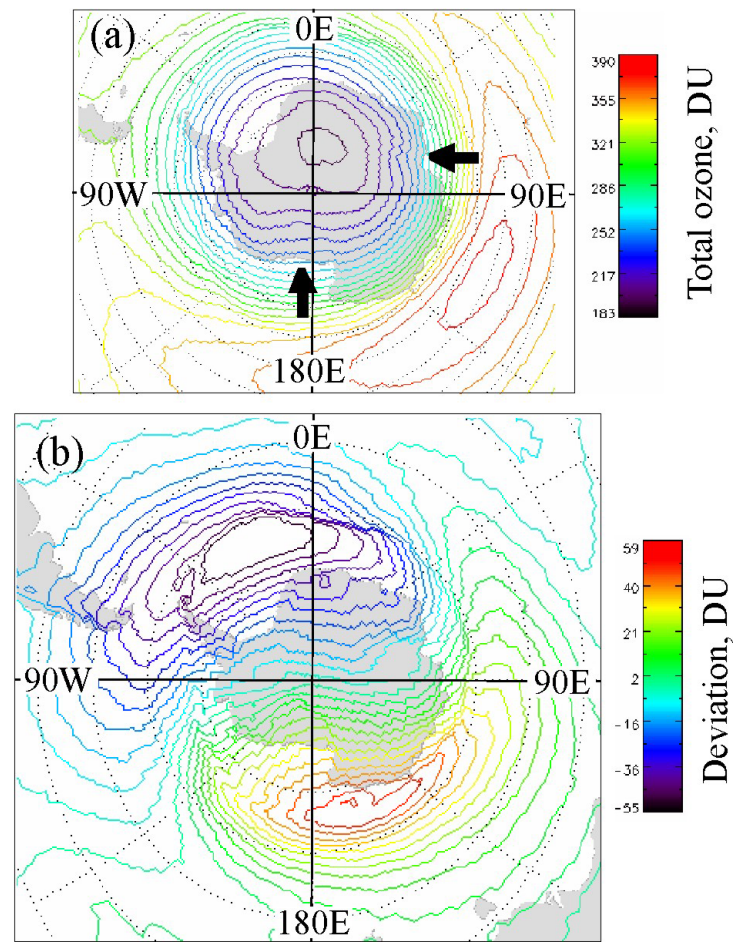

Fig. 7. The 24-year mean distribution of (a) total ozone and (b) its deviation from zonal mean from TOMS data for the springs of 1979-2005. The contour intervals are 10 DU and 5 DU on plots (a) and (b), respectively.

the Antarctic Peninsula and southern tip of South America. Some distinction in contour details between Figs. 7a and $b$ is a result of different resolutions, as the contour intervals are 10 and 5 DU, respectively. On the whole, Fig. $7 \mathrm{~b}$ displays qualitatively the same degree of asymmetry and a spatial structure in the zonal extremes given by statistics at the seven latitudes in Fig. 3b and Fig. 6a.

We note that the ozone distribution in Fig. 7a coincides in general with results presented in the ERA-40 Atlas by Fig. C2 (Kallberg et al., 2005). In a version of the ERA-40 project, the column ozone climatology is given from the annual and seasonal averages of the TOMS data for 1979-2001. The shape of the discrete ozone levels over the inner part of Antarctica has the same characteristic features noted above in Fig. 7a, i.e. contour deviations occur over the Antarctic Peninsula, the Ross Sea and the Amery Ice Shelf.

A feature, which is similar to the continent boundary effect in Fig. 7, has been described by Pudovkin et al. (2004). They have found that the contours of total ozone extend approximately along the boundary of the permafrost region in Eurasia and Canada.

Since the results of Fig. 6 display the planetary wave structure in total ozone, they predominantly characterize disturbances at the lower stratospheric altitudes, where the largest part of column ozone is concentrated (10-20 km, e.g. Salby

\section{Eddy geopotential heights 1979-2005}
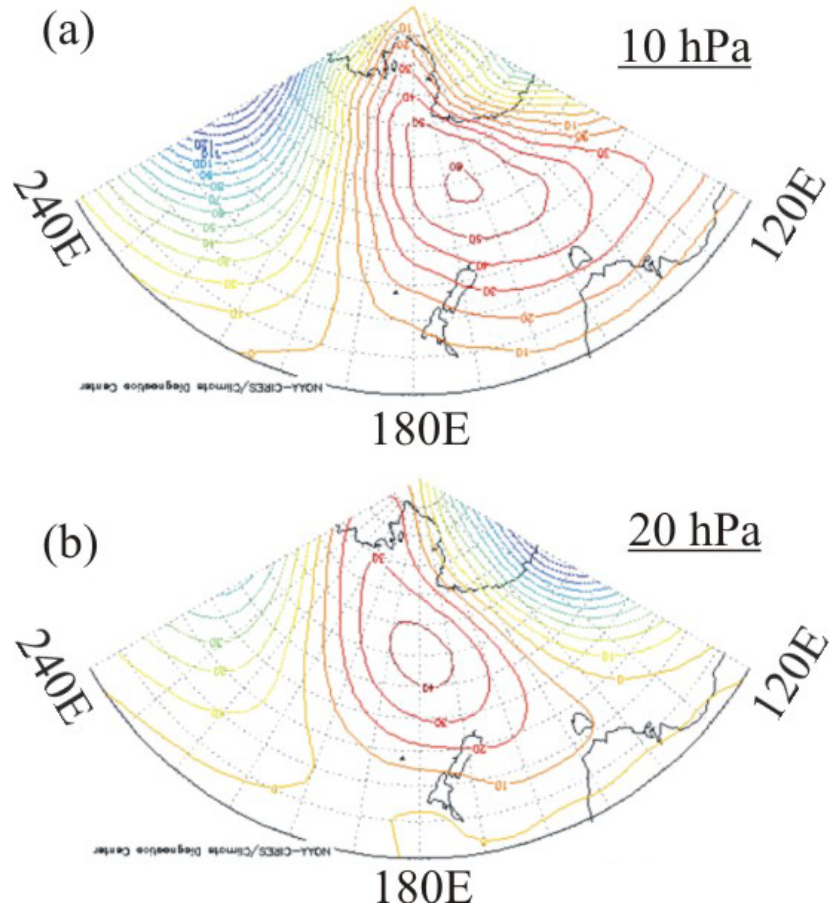

Fig. 8. (a) and (b) Eddy geopotential heights within the sector $120^{\circ} \mathrm{E}-240^{\circ} \mathrm{E}$ at the pressure levels $10 \mathrm{hPa}$ and $20 \mathrm{hPa}$, respectively, NCEP-NCAR reanalysis data.

and Callaghan, 1993). It can be hypothesised that the largescale features of the ozone asymmetry in Figs. 6 and 7 are concerned with the influence of Antarctic orography on the distribution of the stratospheric ozone, unlike the surface and tropospheric contributions to the total column ozone in the continental structures described by Kazimirovsky and Matafonov (1998) and Cuevas et al. (2001).

It has been shown by Francis and Salby (2001) that the thermal and dynamical structure of the lower stratosphere at high southern latitudes are both influenced significantly by Antarctica by the 9.6- $\mu \mathrm{m}$ ozone absorption feature. The sharp temperature contrast due to Antarctica introduces a similar contrast in longwave heating, which shapes the thermal structure in the lower stratosphere and reinforces the polar vortex.

Note that the possible radiative influence of Antarctica can be traced not only to the lower stratosphere, but also to the mid-stratosphere. Regional anomalies in the geopotential height distribution also exhibit coincidence with the continent boundary shape at the pressure levels $20 \mathrm{hPa}$ and $10 \mathrm{hPa}(27 \mathrm{~km}$ and $32 \mathrm{~km}$, respectively, Fig. 8). Based on the observations noted in this section, we speculate that the distribution of total ozone reveals the integrated radiative effect of orography on the atmospheric structure between the tropopause and middle stratosphere over Antarctica. 

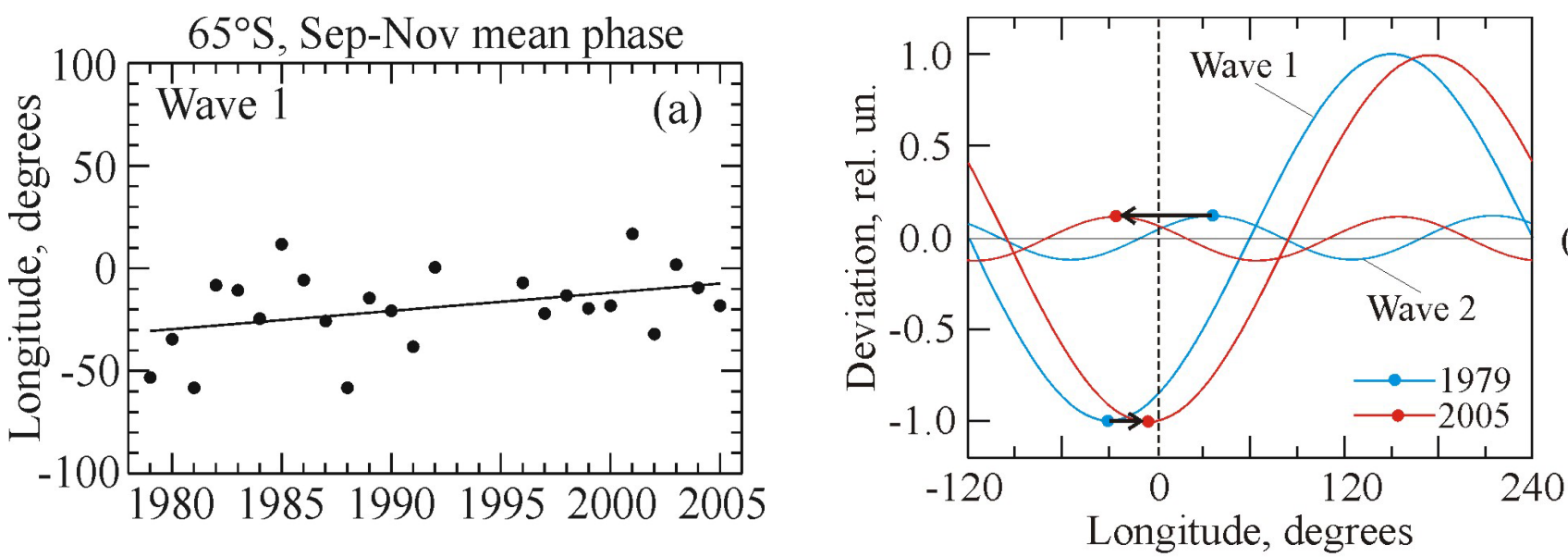

(a)


Fig. 9. Long-term change in the phase of (a) zonal wave 1 and (b) zonal wave 2 at $65^{\circ} \mathrm{S}$.

\subsection{Wave 1 and wave 2 phases}

To identify the cause of the different behaviour of the zonal wave ridge and trough during 1979-2005 (Figs. 5 and 6b) we have analysed the phases of quasi-stationary waves 1 and 2. The daily longitudinal distributions of total ozone for the spring months were used. It can be seen from the standard deviations in Table 3 that most of the phase values show statistically significant shifts at the $2 \sigma$-level. The clear exception is the wave 2 phase at $50^{\circ} \mathrm{S}$. Poleward of $50^{\circ} \mathrm{S}$, the longterm shifts in the phases of wave 1 and wave 2 are in the opposite direction (eastward and westward, respectively). As an example, the phase variations of wave 1 and wave 2 during 1979-2005 at $65^{\circ} \mathrm{S}$ are shown in Fig. 9.

We use this example to consider how the difference in behaviour of the total wave extremes can be produced by a combination of these two harmonics. The mean initial (1979) and final (2005) phases of waves 1 and 2 were estimated from a linear fit (solid lines in Fig. 9).

The pairs of initial and final phases for wave 1 are $30^{\circ} \mathrm{W}$ and $7^{\circ} \mathrm{W}$, and for wave 2 are $36^{\circ} \mathrm{E}$ and $26^{\circ} \mathrm{W}$, respectively (Fig. 10a). The amplitude ratio of wave 2 to wave 1 was taken as 0.12, which follows from Fig. 4b.

A superposition of wave 1 and wave 2 (Fig. 10b) reproduces the main trends observed in the behaviour of the total wave ridge and trough. Initial and final positions of the wave 1+2 extremes in Fig. 10b are very close to those of the total wave at $65^{\circ} \mathrm{S}$ in Fig. 6b. Figure $10 \mathrm{~b}$ demonstrates that the amplitude change between the initial and final positions of the wave sum is small. However, a clear distinction in the position of the wave sum trough appears despite the $12 \%$-contribution of wave 2 . The trough shifts eastward, but the position of the ridge is almost unchanged. Note that wave 2 , in its westward shift, passes in anti-phase (in-phase) with the wave 1 trough (ridge). Such a combination of the amplitudes, initial positions and shift directions of the two sinusoids could give longitudinal stability to the total wave ridge and a noticeable displacement of the total wave trough. 
Table 3. Decadal change of the zonal wave 1 and 2 phase.

\begin{tabular}{ccc}
\hline $\begin{array}{c}\text { Latitude, } \\
{ }^{\circ} \mathrm{S}\end{array}$ & $\begin{array}{c}\text { Wave 1 phase } \\
\text { shift, }{ }^{\circ} \mathrm{E} / \mathrm{dec}\end{array}$ & $\begin{array}{c}\text { Wave 2 phase } \\
\text { shift, }{ }^{\circ} \mathrm{E} / \mathrm{dec}\end{array}$ \\
\hline 50 & $10.5 \pm 5.4$ & $1.7 \pm 11.7$ \\
55 & $15.3 \pm 5.6$ & $-29.2 \pm 14.2$ \\
60 & $13.5 \pm 4.8$ & $-27.7 \pm 13.1$ \\
65 & $8.9 \pm 4.6$ & $-24.2 \pm 8.5$ \\
70 & $7.8 \pm 4.9$ & $-16.2 \pm 5.6$ \\
75 & $6.9 \pm 4.8$ & $-10.5 \pm 5.8$ \\
80 & $9.4 \pm 4.5$ & $-7.3 \pm 3.3$ \\
\hline
\end{tabular}

\section{Discussion}

\subsection{Zonal asymmetry degree}

It follows from Sect. 3 that the cause of the strong disturbances of the total ozone field during the Antarctic spring is not only related to the ozone hole, but also to the longitudinal asymmetry of the ozone maximum at mid- and sub-polar latitudes (Fig. 1). These two ozone anomalies of opposite sign develop almost simultaneously during late winter to spring. The leading processes are chemical ozone loss in the ozone hole and dynamical ozone accumulation in the collar region. There is a mean tendency of the former to displace relative to the pole toward the sector $60^{\circ} \mathrm{W}-0^{\circ} \mathrm{E}$ (zonal minimum in the total ozone) and with a preferred location of the latter within the quadrant $90^{\circ} \mathrm{E}-180^{\circ} \mathrm{E}$ (zonal maximum, Fig. 6a). The two regions tend to be distributed longitudinally in opposite sectors and this zonal asymmetry is produced by quasistationary planetary wave 1 . Both anomalies can occupy the latitude interval $60^{\circ} \mathrm{S}-70^{\circ} \mathrm{S}$ and are dominant poleward (ozone hole) and equatorward (ozone collar).

Climatologically, in the region under consideration this TOC zonal structure has minimum $\mathrm{TOC}_{\min } \sim 200 \mathrm{DU}$ at the latitudes $70^{\circ} \mathrm{S}-80^{\circ} \mathrm{S}$ (Fig. 3a, dashed curve) and maximum $\mathrm{TOC}_{\max } \sim 380 \mathrm{DU}$ at $50^{\circ} \mathrm{S}-60^{\circ} \mathrm{S}$ (Fig. 3a, solid curve). Then the absolute extremes are clearly spaced in latitude.

A characteristic property of the intermediate latitude interval $60^{\circ} \mathrm{S}-70^{\circ} \mathrm{S}$ is the highest zonal difference in the TOC level and difference trend. On the 3-month scale, as shown by Fig. $3 \mathrm{~b}$, the highest zonal wave amplitude $A_{z w}=57.2 \pm 13.5 \mathrm{DU}\left(A_{\text {rel }}=32 \%\right)$ and amplitude trend $9.3 \pm 2.8 \mathrm{DU} /$ decade are observed on average at $65^{\circ} \mathrm{S}$ (see also Table 1). The changes in zonal asymmetry degree include the different TOC level decrease in regions of the zonal extremes.

The larger negative trends are observed in $\mathrm{TOC}_{\min }$ (up to -38 DU/decade, Table 1) and they give a main contribution to zonal mean loss at the high latitudes. This trend in the zonal minimum is chemical in origin, because it relates to the ozone hole, as mentioned above.
At the lower latitudes of zonal maximum the trends are much smaller and symmetric $\left(50^{\circ} \mathrm{S}:-8.4 \pm 3.6\right.$ and $-8.5 \pm 2.0 \mathrm{DU} / \mathrm{decade}$ in $\mathrm{TOC}_{\max }$ and $\mathrm{TOC}_{\min }$, respectively) or somewhat asymmetric $\left(55^{\circ} \mathrm{S}:-12.0 \pm 4.2\right.$ and $-17.4 \pm 2.6 \mathrm{DU} /$ decade, respectively). So, the dynamically formed ozone collar does not contribute significantly to trend asymmetry and displays the mean ozone loss outside the polar vortex. For example, in the collar region the values of $-(8-12)$ DU/decade correspond to $-(0.2-0.3) \% / y e a r$, which coincides closely with the linear trend $-(0.4-0.5) \% / y e a r$ given by Fig. 3-3 in WMO (2003) for Antarctic spring and latitudes $50^{\circ} \mathrm{S}-55^{\circ} \mathrm{S}$.

By the year 2000, this zonal difference in negative trends increased the maximal difference between the high and low total ozone to about $100-140 \mathrm{DU}(30-40 \%)$. It is possible that the asymmetry has reached a maximal degree now, because the maximum size of the ozone hole, as well as ozone losses, have essentially leveled off during the last decade (WMO, 2003; Yang et al., 2005). However, the large TOC zonal redistribution during the Antarctic spring, which is repeated from year to year, should be emphasized.

Asymmetric structure and seasonality of these changes could influence the thermal and dynamical structure of the lower stratosphere (Salby and Callaghan, 2004). First of all, the ozone change is accompanied by a temperature change in the lower stratosphere. In particular, a strong cooling (of order 6-10 K) in the lower stratosphere $(\sim 12-21 \mathrm{~km})$ has been observed over Antarctica during spring since approximately 1985 (Randel and Wu, 1999). One can assume that significant zonal asymmetry in the lower stratosphere temperature and tropopause height exists in accordance with the TOC asymmetry. How the degree of this persistent thermal and dynamical stress acts on the polar vortex is worthy of further study.

Additionally, as it is widely known, ozone affects the surface ultraviolet irradiance and this is of importance for living systems (Prause et al., 1999; Zaller et al., 2002). High levels of UV irradiance were observed during September and October 2000, when the edge of the ozone hole moved over the southern tip of South America (Bernhard et al., 2000). From our results, the changes in the TOC minimum level and location occur more over the Weddell Sea towards unpopulated open ocean, which should offset the maximum UV exposure. On the other hand, the TOC maximum characteristics indicate a possibility of the surface UV deficit in the eastern subAntarctic region during spring. The influence of changes in ozone asymmetry on marine biology needs a separate study.

\subsection{Continental boundary effect}

The results of Sect. 4.2 demonstrate the possibility of connection between Antarctic orography and the quasistationary zonal distribution of total ozone at sub-polar and polar latitudes. Patterns in the structure of the zonal wave extremes have been revealed by the statistics for the spring-time 
Trop. Pressure 1979-1983, Month=9-11

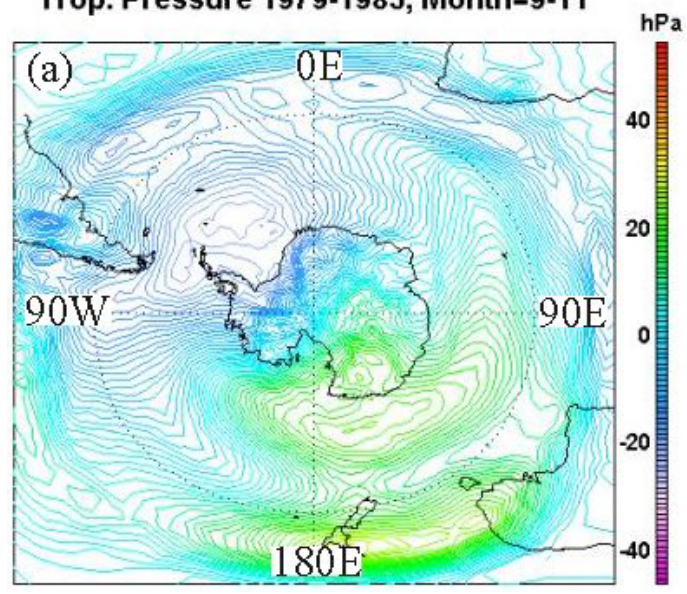

Trop. Pressure 2001-2005, Month=9-11

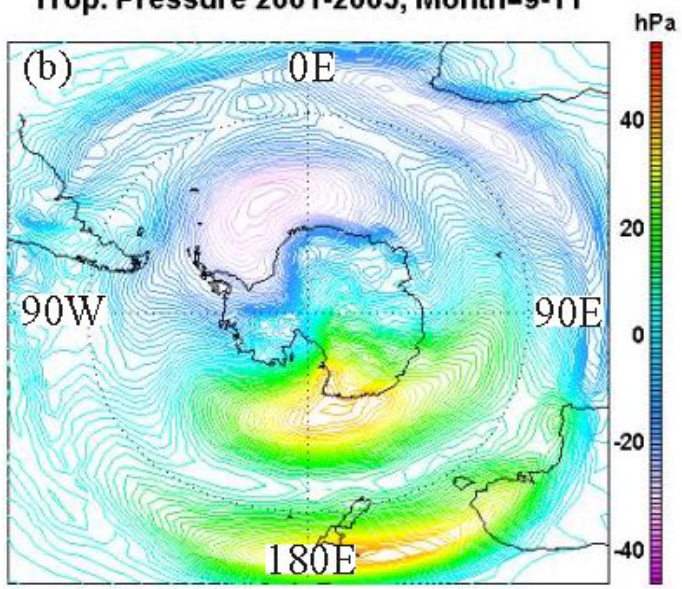

Fig. 11. Eddy field of tropopause pressure for September-November (a) 1979-1983 and (b) 2001-2005 from the NCEP-NCAR reanalysis data.

total ozone distribution along seven latitudes between $50^{\circ} \mathrm{S}$ and $80^{\circ} \mathrm{S}$ during 24 years. A spatial resolution of $5^{\circ}$ in latitude reveals the largest-scale features of zonal asymmetry, which are confirmed by independent data in Fig. 11. The zonal deviation of spring tropopause pressure is presented by the NCEP-NCAR reanalysis data. The 5-year averages of the eddy field over 1979-1983 (Fig. 11a) and 20012005 (Fig. 11b) have been created to illustrate the long-term changes in the tropopause zonal asymmetry.

It can be seen from Fig. 11 that the zonal extremes in the tropopause pressure take the same longitudinal sectors and peak value latitude as in the total ozone in Fig. 7b. The well known inverse relationship between the tropopause height and the total ozone (Hoinka, 1998; Varotsos et al., 2004) is confirmed by this comparison. However, the tropopause pressure minimum (tropopause height maximum) over the Weddell Sea exhibits more clearly a coastline effect in Fig. 11 and this effect has become stronger in the most recent decade (Fig. 11b). The detailed analysis of this tendency is outside the scope of the present work.

Although the ozone minimum in Fig. $7 \mathrm{~b}$ does not exhibit as sharp a boundary effect as for the tropopause in Fig. 11, the influence of the Antarctic Peninsula can be noted from the meridionally distributed $\mathrm{TOC}_{\text {min }}$ positions between $65^{\circ} \mathrm{S}$ and $80^{\circ} \mathrm{S}$ in Fig. 6. On a decadal scale, the minimum moves off the Antarctic Peninsula, the signature of the eastern coastline of the Weddell Sea is weakened and the influence of the western coastline can be perceived in the final $\mathrm{TOC}_{\min }$ positions in Figs. 6b, d, e. The latter is clearly marked by an increased tropopause pressure gradient along $\sim 0^{\circ} \mathrm{E}$ in Fig. $11 b$.

Note that the longitudinal variability of the extremes decreases poleward, especially in the region of TOC maximum (see the standard deviations in Fig. 6a and in Table 2). This means that the stationarity of the zonal wave becomes stronger approaching the continental boundary. The zonal maximum has very small longitudinal deviations at latitudes $70^{\circ} \mathrm{S}, 75^{\circ} \mathrm{S}$ and $80^{\circ} \mathrm{S}$. At these latitudes, an approximately meridional distribution along the Ross Sea coastline is observed (Fig. 6). Such a meridional alignment of the TOC zonal extremes allows us to infer that on the whole, the axis of the TOC zonal asymmetry at the high southern latitudes tends to be oriented close to meridionally oriented parts of the continental boundary.

As has been mentioned in Sect. 4.2, the radiative influence of Antarctic orography can contribute to this effect, which could range from the tropopause to the middle stratosphere. Francis and Salby (2001) have concluded that Antarctica's radiative impact contributes to shaping the ozone column abundance. This implies the existence of a gradient in the total ozone distribution over the continental boundary due to the sharp land-sea temperature gradient. In the region of the TOC zonal minimum, the radiative response to orography must be weaker due to the lower ozone concentration. This possibly causes the absence of so clear a continental boundary effect in the total ozone (Fig. 7), as in the tropopause (Fig. 11) in the sector $0^{\circ}-60^{\circ} \mathrm{W}$.

Obviously, the sharpness of the ozone gradient at stratospheric altitudes should be less than the land-ocean temperature gradient. Nevertheless, it could be expected that the stratospheric ozone gradient is narrow enough over the continent boundary in comparison with the horizontal size of the Antarctica. In consideration of the ozone layer over Antarctica, one can compare the vertical and horizontal scales. If the distance between the surface and mid-stratosphere is $\sim 40 \mathrm{~km}$ and the horizontal size of Antarctica is $\sim 4000 \mathrm{~km}$, their ratio is 1:100. The ratio for the lower stratosphere and tropopause is even smaller. One could say that the lower stratosphere is a very thin shell over the Antarctic continent and is sufficiently close to the surface to be sensitive to sharp 
temperature contrasts at the surface. Figures 6 and 11 provide evidence for a possible radiative influence of the surface temperature gradient on the total ozone and tropopause.

Note that the meridionally oriented elements of Antarctic orography have approximately 15 -degree latitude intervals in the sectors of the Weddell Sea and Ross Sea (including their respective ice shelf areas). This is greater than $1500 \mathrm{~km}$ and more than $1 / 3$ of the characteristic size of Antarctica (about $4000 \mathrm{~km}$ ). In the context of radiative coupling, such a spatial scale can play a role in the formation of radially oriented anomalies in the thermal structure of the lower stratosphere. This anomaly could be considered as a radial barrier, which is able to fix or stabilize the zonal wave ridge and trough position under prolonged action. Model experiments need to examine this hypothesis.

Although orography can also impose stationary atmospheric disturbances, which spread upward, their longitudinal position cannot remain fixed due to the westward phase tilt with altitude. This is the reason why the vertical propagation of an orographically forced stationary wave cannot provide a direct projection of the orographic features into stratosphere. A radiative influence is a more reasonable mechanism for the interpretation of the effect discussed.

The possible influence of Antarctic orography on the total ozone asymmetry decreases from latitudes $65^{\circ} \mathrm{S}$ to $50^{\circ} \mathrm{S}$ and the tendency of the near-radial distribution of extreme positions is replaced by a westward-directed pattern (Fig. 6). This change could be caused by the influence of the two other mid-latitude continents (South America and Australia, located in the neighbourhood of the TOC zonal minimum and maximum, respectively). The fact that the stationary Rossby waves within the hemisphere tend to occur on great circle paths (Held et al., 2002) can also play a role. This aspect needs further analysis.

\subsection{Eastward shift}

The correlation of total ozone with tropopause height provides a means of examining the behaviour of the TOC zonal extremes with independent data. The long-term eastward shift of the TOC zonal minimum is worthy of special notice.

Eddy fields of tropopause pressure in the spring months show a decadal eastward shift in the region of pressure minimum between the average of 1979-1983 and 2001-2005 (Figs. 11a and b, respectively). Note that the western edge of the tropopause pressure minimum area is bordered by the Antarctic Peninsula on both plots, but the peak value and the eastern edge are shifted to the east. Thus, the same tendency is observed at the tropopause and lower stratosphere levels, although the shift distance in ozone data (Fig. 6b) is about twice as much as in tropopause pressure (Fig. 11).

This comparison cannot indicate the altitude at which the eastward shift originates. It should be noted that the global climate changes of the last decades have been accompanied by the development of regional anomalies in both hemi- spheres, including the horizontal redistribution of the atmospheric centres of action ( $\mathrm{Hu}$ and $\mathrm{Wu}, 2004$; Cassou et al., 2004; Bromwich et al., 2004). The poles of the North Atlantic oscillation (NAO), the Azores high and Iceland low, shifted eastward by $30^{\circ}$ of longitude toward Europe during 1980s-1990s relative to 1950s-1960s (Cassou et al., 2004). This tendency appears for the NAO+ climate regime and model results suggest this has a synoptic origin. Global warming scenario simulation reproduces the north-eastward shift of these two centres of action by $10^{\circ}$ to $20^{\circ}$ in latitude and $30^{\circ}$ to $40^{\circ}$ in longitude in the first half of the 21 st century relative to the last half of the 20th century $(\mathrm{Hu}$ and $\mathrm{Wu}$, 2004).

Anomalous warming is a dominant mode of climate change in the Antarctic Peninsula region: $0.37 \pm 0.16^{\circ} \mathrm{C} /$ decade in comparison with the global mean tendency for the last century of $0.06 \pm 0.02^{\circ} \mathrm{C} /$ decade (Vaughan et al., 2003). During the past decades, the near-surface warming has been different at the western and eastern side of the Peninsula (Orr et al., 2004, and references there). From Bromwich et al. (2004), the anomalies of the 500-hPa geopotential heights show an eastward shift between $130^{\circ} \mathrm{W}$ and $90^{\circ} \mathrm{W}$, i.e. in the sector, which is located west of the Antarctic Peninsula. It should be noted that the sector to the east of the Peninsula $\left(60^{\circ} \mathrm{W}-0^{\circ} \mathrm{E}\right)$ is a region where the ozone minimum shifts eastward. To our knowledge, no known atmospheric processes with a similar long-term shift take place in the region of the Weddell Sea.

Although the tendencies in total ozone show some common features with the climate changes of Western Antarctica, the results of this work do not directly identify the processes that are responsible for the eastward shift of the TOC zonal minimum. Further analysis is necessary to define how this tendency could be influenced by the decadal changes in the different atmospheric layers. To draw attention to behaviour of the first zonal harmonics 1 and 2 (Figs. 9 and 10) would be expedient.

\section{Conclusion}

Total ozone data from TOMS measurements spanning 19792005 show the occurrence of the two zonally asymmetric anomalies in the total ozone field during the Antarctic spring. The mid-latitude collar of ozone-rich air occupies eastern longitudes, with a mean quasi-stationary location in the quadrant $90^{\circ} \mathrm{E}-180^{\circ} \mathrm{E}$. An area of depleted ozone (ozone hole) is responsible for the zonal anomaly of low ozone in the sector $0^{\circ}-60^{\circ} \mathrm{W}$. The steady displacement and elongation of the ozone hole under the influence of the planetary waves takes place toward this sector. Almost a synchronous development of the two anomalies in the late southern winter and spring can produce a zonal difference in the total ozone level up to $\sim 200 \mathrm{DU}$. 
The mean zonal asymmetry of the total ozone has been statistically analyzed using TOMS data over the 24 springs in the 1979-2005 period. The amplitude of the zonal wave and longitudinal position of the wave extremes at the seven latitudes with 5-degree intervals between $50^{\circ} \mathrm{S}$ and $80^{\circ} \mathrm{S}$ have been determined. Statistics of the quasi-stationary wave characteristics for the individual latitudes allows a quantitative description of the total ozone asymmetry, particularly the degree of asymmetry, its structure and temporal behaviour. Although the latitudinal resolution is limited to $5^{\circ}$, some characteristic features and tendencies have been revealed.

On average over 1979-2005, a maximum of 114 DU is observed in the spring asymmetry at $65^{\circ} \mathrm{S}$. Since the asymmetry is much lower in other seasons, the strong increase in the asymmetry in spring is one of the climatological features of the total ozone distribution in the Antarctic region. This can produce quasi-stationary anomalies in the lower stratosphere thermal regime and dynamical structure, as well in the regional anomalies in surface UV-irradiance. These effects should be estimated in further analysis, particularly over the zone of the highest ozone asymmetry between $60^{\circ} \mathrm{S}$ and $70^{\circ} \mathrm{S}$.

Statistics for 1979-2005 show a significant eastward shift of the total ozone minimum in the Weddell Sea - South Atlantic sector with a mean shift distance of about $45^{\circ}$. The zonal maximum exhibits relatively high stationarity within the quadrant $90^{\circ} \mathrm{E}-180^{\circ} \mathrm{E}$. Although a tropospheric source of the eastward shift had not been identified in this work, distinct behaviour of the two extremes can be interpreted analytically by the opposite drift direction of the quasi-stationary wave 1 and wave 2 .

The geographical distribution of the extreme positions for the seven latitudes shows that (i) the total ozone zonal extremes exhibit sensitivity to the shape of the Antarctic continental boundary, (ii) the stationarity of the extremes increases poleward approaching the edge of continent and (iii) at high latitudes, the zonal extremes tend to follow the meridionally oriented elements of orography.

It is hypothesised that the radiative influence of Antarctica contributes to the formation of this pattern. Anomalies in the horizontal structure of the tropopause that are related to orography support the existence of such an influence. At the same time, the atmospheric pressure systems do not show conformity with the quasi-stationary zonal asymmetry in total ozone.

The main processes involved in TOC asymmetry formation during Antarctic spring are 1) chemical ozone losses in the ozone hole, 2) dynamical accumulation of ozone rich air in the collar region, 3 ) persistent zonal separation of the two ozone anomalies by quasi-stationary planetary waves, 4) opposite direction of the decadal zonal drift of the first two harmonics and 5) a possible radiative influence of the sharp temperature gradient at the continent boundary on the total wave ridge and trough structure and position over Antarctica.
Acknowledgements. NCEP Reanalysis data provided by the NOAA-CIRES Climate Diagnostics Center, Boulder, Colorado, USA, from their Web site at http://www.cdc.noaa.gov. TOMS data have been obtained from the NASA Web site http://toms.gsfc.nasa. gov. This research was partly made in the framework of the SCAR ICESTAR Program. The work was supported in part by the National Antarctic Scientific Center of the Ukraine, project N/2-2005, National Taras Shevchenko University of Kyiv, project 06BF05112, by Grant of Ministry Education and Science of Ukraine DFFD F7/362-2001, by Grant Greece-Ukraine M/86-2006, and Australian Antarctic Science project 737.

Topical Editor U.-P. Hoppe thanks two referees for their help in evaluating this paper.

\section{References}

Bernhard, G., Booth, C. R., and Ehramjian, J. C.: Changes in Antarctic UV levels in relation to ozone hole characteristics, Proceedings of the SPARC 2000 2nd General Assembly, Mar del Plata, Argentina, http://www.aero.jussieu.fr $/ \sim$ sparc/ SPARC2000_new, November 2000.

Bromwich, D. H., Monaghan, A. J., and Guo, Z.: Modeling the ENSO modulation of Antarctic climate in the late 1990s with the Polar MM5, J. Climate, 17, 109-132, 2004.

Calisesi, Y., Wernli, H., and Niklaus Kampfer, N.: Midstratospheric ozone variability over Bern related to planetary wave activity during the winters 1994-1995 to 1998-1999, J. Geophys. Res., 106, 7903-7916, 2001.

Cassou, C., Terray, L., Hurrell, J. W., and Deser, C.: North Atlantic winter climate regimes: spatial asymmetry, stationarity with time, and oceanic forcing, J. Climate, 17, 1055-1068, 2004.

Cuevas, E., Gil, M., Rodriguez, J., Navarro, M., and Hoinka, K. P.: Sea-land total ozone differences from TOMS: GHOST effect, J. Geophys. Res., 106, 27 745-27 756, 2001.

Efstathiou, M. N., Varotsos, C. A., Singh, R. P., Cracknell, A. P., and Tzanis, C.: On the longitude dependence of total ozone trends over middle-latitudes, Int. J. Remote Sens., 24, 13611367, 2003.

Engelen, R. J.: The effect of planetary waves on the total ozone zonal deviations in the presence of a persistent blocking anticyclone system, J. Geophys. Res., 101, 28 775-28 784, 1996.

Francis, G. N. and Salby M. L.: Radiative influence of Antarctica on the polar-night vortex, J. Atmos. Sci., 58, 1300-1309, 2001.

Grytsai, A., Grytsai, Z., Evtushevsky, A., and Milinevsky G.: Interannual variability of planetary waves in the ozone layer at $65^{\circ} \mathrm{S}$, Int. J. Remote Sens., 26, 3377-3387, 2005.

Grytsai, A., Evtushevsky, A., Milinevsky, G., and Agapitov, A.: Longitudinal position of the quasi-stationary wave extremes over Antarctic region from the TOMS total ozone, Int. J. Remote Sens., 28, doi:10.1080/01431160600768021, available at: http: //www.informaworld.com/10.1080/01431160600768021, 2007.

Held, I. M., Ting, M., and Wang, H.: Northern winter stationary waves: theory and modeling, J. Climate, 15, 2125-2144, 2002.

Hoinka, K. P.: Statistics of the global tropopause pressure, Mon. Wea. Rev., 126, 3303-3325, 1998.

Holton, J. R. Haynes, P. H., McIntyre, M. E., Douglass, A. R., Rood, R. E., and Pfister, L.: Stratosphere-troposphere exchange, Rev. Geophys., 33, 403-439, 1995. 
Hood, L. L. and Zaff D. A.: Lower stratospheric stationary waves and the longitude dependence of ozone trends in winter, J. Geophys. Res., 100, 25 791-25 800, 1995.

$\mathrm{Hu}, \mathrm{Z} . \mathrm{Z}$. and $\mathrm{Wu}, \mathrm{Z}$. : The intensification and shift of the annual North Atlantic Oscillation in a global warming scenario simulation, Tellus, 56A, 112-124, 2004.

James, P. M., Peters, D., and Waugh D. W.: Very low ozone episodes due to polar vortex displacement, Tellus, 52B, 11231137, 2000.

Kallberg, P., Berrisford, P., Hoskins, B., Simmons, A., Uppala, S., Lamy-Thepaut, S., and Hine, R.: ERA-40 Atlas, ERA-40 Project Report Series No. 19, European Centre for Medium Range Weather Forecasts, England, UK, 191 p., 2005.

Kazimirovskii, E. S. and Matafonov, G. K.: Continental and orographic structures in the global distribution of the total ozone content, Doklady Earth Sciences, 361A, 855-857, 1998.

Mariotti, A., Mechoso, C. R., Legras, B., and Daniel, V.: The evolution of the ozone "collar" in the Antarctic lower stratosphere during early August 1994, J. Atmos. Sci., 57, 402-414, 2000.

Niu, X., Frederick, J. E., Stein, M. L., and Tiao, G. C.: Trends in column ozone based on TOMS data: dependence on month, latitude and longitude, J. Geophys. Res., 97, 14 661-14 669, 1992.

Orr, A., Cresswell, D., Marshall, G. J., Hunt, J. C. R., Sommeria, J., Wang, C. G., and Light M.: A 'low-level' explanation for the recent large warming trend over the western Antarctic Peninsula involving blocked winds and changes in zonal circulation, Geophys. Res. Lett., 31, L06204, doi:10.1029/2003GL019160, 2004.

Perez, A., Crino, E., Aguirre de Carcer, I., and Jaque, F.: Low-ozone events and three-dimensional transport at midlatitudes of South America during springs of 1996 and 1997, J. Geophys. Res., 105, 4553-4561, 2000.

Peters, D. and Entzian, G.: Longitude-dependent decadal changes of total ozone in boreal winter months during 1979-1992, J. Climate, 12, 1038-1048, 1999.

Prause, A. R., Scourfield, M. W. J., Bodeker, G. E., and Diab, R. D.: Surface UV-B irradiance and total column ozone above SANAE, Antarctica, South African J. Sci., 95, 26-30, 1999.

Pudovkin, M. I., Anokhin, S. G., and Starkov, G. V.: Permafrost influence on the total ozone in the atmosphere, Geom. Aeronom., 44, 87-92, 2004.
Randel, W. J. and Wu, F.: Cooling of the Arctic and Antarctic polar stratospheres due to ozone depletion, J. Climate, 12, 1467-1479, 1999.

Salby, M. L. and Callaghan, P. F.: Fluctuations of total ozone and their relationship to stratospheric air motions, J. Geophys. Res., 98, 2715-2727, 1993.

Salby, M. L. and Callaghan, P. F.: Interannual changes of the stratospheric circulation: influence on the Tropics and Southern Hemisphere, J. Climate, 17, 952-964, 2004.

Varotsos, C., Cartalis, C., Vlamakis, A., Tzanis, C., and Keramitsoglou, I.: The long-term coupling between column ozone and tropopause properties, J. Climate, 17, 3843-3854, 2004.

Vaughan, D. G., Marshall, G. J., Connolley, W. M., Parkinson, C., Mulvaney, R., Hodgson, D. A., King, J. C., Pudsey, C. J., and Turner, J.: Recent rapid regional climate warming on the Antarctic Peninsula, Climatic Change, 60, 243-274, doi:10.1023/A:1026021217991, 2003.

Vigliarolo, P. K., Vera, C. S., and Diaz, S. B.: Synoptic-scale variability and its relationship with total ozone and Antarctic vortex displacements, Mon. Wea. Rev., 133, 2374-2386, 2005.

Waugh, D. W. and Randel, W. J.: Climatology of Arctic and Antarctic polar vortices using elliptical diagnostics, J. Atmos. Sci., 56, 1594-1613, 1999.

Wirth, V.: Quasi-stationary planetary waves in total ozone and their correlation with lower stratospheric temperature, J. Geophys. Res., 98, 8873-8882, 1993.

WMO (World Meteorological Organization): Scientific assessment of ozone depletion: 2002, Report No. 47, Geneva, 2003.

Yang, E.-S., Cunnold, D. M., Newchurch, M. J., and Salawitch, R. J.: Change in ozone trends at southern high latitudes, Geophys. Res. Lett., 32, L12812, doi:10.1029/2004GL022296, 2005.

Zaller, J. G., Caldwell, M. M., Flint, S. D., Scopel, A. L., Salo, O. E., and Ballare, C. L.: Solar UV-B radiation affects belowground parameters in a fen ecosystem in Tirra del Fuego, Argentina: implications of stratospheric ozone depletion, Global Change Biology, 8, 867-871, 2002. 